\title{
A EXPANSÃO DA EDUCAÇÃO SUPERIOR BRASILEIRA A PARTIR DOS ANOS 90: DEMOCRATIZAÇÃO OU MASSIFICAÇÃO?
}

\author{
THE EXPANSION OF BRAZILIAN HIGHER EDUCATION IN THE 90s: \\ DEMOCRATIZATION OR MASSIFICATION?
}

\section{LA EXPANSIÓN DE LA EDUCACIÓN SUPERIOR BRASILEÑA A PARTIR DE LOS AÑOS 90: DEMOCRATIZACIÓN O MASIFICACIÓN?}

\author{
Gabriela Fernanda Silva Borges \\ E-mail: gabrielaborges@iftm.edu.br \\ Elisa Antônia Ribeiro \\ E-mail: elisa.ribeiro@iftm.edu.br \\ Instituto Federal de Educação, Ciência e Tecnologia do Triângulo Mineiro - IFTM
}

\begin{abstract}
RESUMO
O presente artigo objetiva retratar e discutir a expansão da educação superior no Brasil a partir da década de 1990 tendo como um dos elementos estruturantes dessa expansão de cunho privatista as orientações de cariz neoliberal repassadas pelos organismos internacionais aos países em desenvolvimento. Pretende-se ainda refletir sobre os preceitos democratização e massificação deste nível de ensino numa perspectiva de análise comparativa. Realizou-se pesquisa bibliográfica a respeito da questão da mercantilização da educação superior em contraposição à educação superior como direito social, segundo autores como PAULA (2011), SILVA JÚNIOR e SGUISSARDI (2000), SGUISSARDI (2015) e REIS ET AL (2014), bem como o levantamento estatístico sobre a expansão mediante consulta e extração de dados disponibilizados pelo Instituto Nacional de Estudos e Pesquisas Educacionais Anísio Teixeira (INEP). Discutiu-se o papel do Estado perante a sociedade e as implicações do ideário neoliberal na formulação das políticas educacionais, especificamente, na educação superior. Aponta-se que a democratização do acesso à educação é uma via, não exclusiva, para a promoção do crescimento econômico, desenvolvimento da sociedade e redução das desigualdades sociais, para tanto faz-se necessário ampliar o papel do Estado na busca pela inclusão de grupos sub-representados na educação superior gratuita e de qualidade.
\end{abstract}

PALAVRAS-CHAVE: Educação superior. Democratização. Neoliberalismo.

\section{ABSTRACT}

The present article aims at portraying and discussing the expansion of higher education in Brazil from the 1990s, having as one of the structuring elements of this privatizing expansion the neoliberal orientations passed on by international organizations to developing countries. It is also intended to reflect on the precepts democratization and massification of this level of education in a perspective of comparative analysis. According to authors such as PAULA (2011), SILVA JÚNIOR and SGUISSARDI (2000), SGUISSARDI (2015) and REISET AL (2014), a bibliographical research was carried out on the question of the commercialization of higher education as opposed to higher education as a social right. , as well as the statistical survey on the expansion through consultation and extraction of data made available by the National Institute of Educational Studies and Research Anisio Teixeira (INEP). The role of the State in relation to society and the implications of the neoliberal ideology in the formulation of educational policies, specifically in higher education, were discussed. It is pointed out that the democratization of access to education is a non-exclusive way to promote economic growth, the development of society and the reduction of social inequalities, so it is necessary to broaden the role of the State in the search for the inclusion of groups under-represented in free and quality higher education.

KEYWORDS: Higher education. Democratization. Neoliberalism.

\section{RESUMEN}

El presente artículo objetiva retratar y discutir la expansión de la educación superior en Brasil a partir de la década de 1990 teniendo como uno de los elementos estructurantes de esa expansión de cuño privatista las orientaciones de cariz 
neoliberal repasadas por los organismos internacionales a los países en desarrollo. Se pretende también reflexionar sobre los preceptos democratización y masificación de este nivel de enseñanza desde una perspectiva de análisis comparativo. Se realizó una investigación bibliográfica sobre la cuestión de la mercantilización de la educación superior en contraposición a la educación superior como derecho social, según autores como PAULA (2011), SILVA JÚNIOR y SGUISSARDI (2000), SGUISSARDI (2015) y REIS ET AL (2014), así como el levantamiento estadístico sobre la expansión mediante consulta y extracción de datos disponibilizados por el Instituto Nacional de Estudios $e$ Investigaciones Educativas Anísio Teixeira (INEP). Se discutió el papel del Estado ante la sociedad y las implicaciones del ideario neoliberal en la formulación de las políticas educativas, específicamente, en la educación superior. Se apunta que la democratización del acceso a la educación es una vía no exclusiva para la promoción del crecimiento económico, el desarrollo de la sociedad y la reducción de las desigualdades sociales, para ello se hace necesario ampliar el papel del Estado en la búsqueda de la inclusión de grupos sub-representados en la educación superior gratuita y de calidad.

PALABRAS-CLAVE: Educación superior. Democratización. Neoliberalismo.

\section{INTRODUÇÃ̃O}

O presente artigo pretende apresentar dados que comprovam a expansão da educação superior no Brasil a partir da década de 1990, considerando as orientações de cariz neoliberal repassadas pelos organismos internacionais aos países em desenvolvimento.

A problematização definida foi refletir se as características da expansão da educação superior brasileira marcam um processo de democratização ou apenas um processo de massificação deste nível de ensino, considerando o contexto de desigualdade de acesso e permanência da educação superior no país.

Para tanto, realizamos pesquisa bibliográfica acerca da questão da mercantilização da educação superior em contraposição à educação superior como direito social. Além disso, sucedemos ao levantamento de dados estatísticos por meio de publicações do Instituto Nacional de Estudos e Pesquisas Educacionais Anísio Teixeira (INEP), a fim de demonstrarmos o crescimento quantitativo das instituições de educação superior, considerando a categoria administrativa, bem como a evolução no número de vagas e matrículas na educação superior brasileira no período compreendido entre 1990 e 2017.

A partir dos dados coletados é possível verificar que o processo de democratização vai muito além de dados meramente quantitativos, pois, não basta o incremento no número de matrículas e vagas. É necessário que os grupos marginalizados da educação superior brasileira sejam incluídos de forma democrática neste nível de ensino. Neste cenário, as políticas públicas educacionais devem disponibilizar meios e oportunidades de acesso e permanência à educação superior do país.

\section{A EDUCAÇÃO SUPERIOR COMO DIREITO SOCIAL}

\begin{tabular}{l|l|l|l|l|l} 
(C) Revista Triângulo & Uberaba, Minas Gerais & v.12 & n.1 & p. $103-118$ & 2019
\end{tabular}




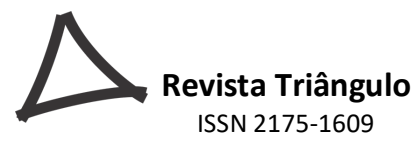

Desigualdade social não está relacionada unicamente à desigualdade econômico-financeira; estão neste contexto as desigualdades de gênero, de etnia, física e a desigualdade educacional. No Brasil, a desigualdade está presente em diversas áreas, inclusive na educação, atingindo a parcela da sociedade que não consegue se inserir na educação formal e principalmente na educação superior.

Além das condições socioeconômicas são causas da desigualdade e exclusão no acesso e permanência à educação superior: os fatores geográficos, étnicos e físicos; a deficiência de qualidade na educação básica; os altos níveis de seletividade dos sistemas de ensino e a mercantilização da educação superior.

Apesar de prevista constitucionalmente como direito fundamental de natureza social, verificase que a educação superior é a que está mais distante de chegar à sua universalização. Nota-se que o crescimento da oferta de vagas na educação superior está abaixo do previsto no Plano de Educação Nacional ${ }^{1}$, aprovado pela Lei $n^{0} 13.005 / 2014$. Além disso, a expansão da oferta de vagas foi maior na iniciativa privada de ensino ${ }^{2}$. Assim, se, por um lado a educação superior, por ser gratuita em instituições públicas é vista como um direito social, por outro, a maior parcela da sociedade só consegue este acesso por meio de pagamento dos estudos em instituições privadas.

Para REIS ET AL (2014, p. 90), “uma vez que a educação é entendida como direito, não é possível que a sociedade possa compreendê-la como mercadoria ou objeto a ser coordenado pelo mercado" por isso, ações que garantam o respeito às assimetrias sociais devem emergir na forma de garantia do acesso e permanência no ensino superior.

Segundo LIMA e BIANCHINI (2016, p. 501), “as desigualdades sociais problematizam o princípio democrático da igualdade de condições de acesso e justificam ação pública diferenciada para atender direitos coletivos para grupos ou classes desiguais". Desta forma, ações que contemplam aumento de vagas nos cursos de graduação, iniciativas de combate à evasão e promoção de políticas de democratização do acesso e permanência tem mostrado sua importância na busca por uma reorganização social através da educação.

\footnotetext{
${ }^{1}$ A meta 12 do Plano Nacional de Educação (PNE) estipula elevar a taxa bruta de matrícula na educação superior para $50 \%$ e a taxa líquida para 33\% da população de 18 a 24 anos, assegurada a qualidade da oferta e expansão para, pelo menos, $40 \%$ das novas matrículas, no segmento público. De 2009 a 2015 houve um aumento de 6,5 pontos percentuais, atingindo $34,6 \%$ de matrículas na educação superior, o que pode ser considerado um ritmo insuficiente para o cumprimento da meta em 2024. (MINISTÉRIO DA EDUCAÇÃO - MEC).

${ }^{2}$ De acordo com o Censo da Educação Superior em 2017, a rede privada ofertou 92,4\% do total de vagas em cursos de graduação em 2017. A rede pública correspondeu a 7,6\% das vagas ofertadas pelas instituições de educação superior (INSTITUTO NACIONAL DE ESTUDOS E PESQUISAS EDUCACIONAIS ANISIO TEIXEIRA - INEP).
}

\begin{tabular}{l|l|l|l|l|l|} 
CC Revista Triângulo & Uberaba, Minas Gerais & v.12 & n.1 & p. $103-118$ & 2019
\end{tabular}


As políticas de inclusão e diminuição das desigualdades sociais não podem deixar de priorizar o acesso à educação e aos bens culturais, em especial o acesso e a permanência na educação superior. $\mathrm{O}$ acesso e a permanência no ensino superior devem ser considerados elementos centrais nos aspectos relacionados à relevância $\mathrm{e}$ responsabilidade social das instituições de educação superior, pois cada cidadão bem formado poderá ter melhores oportunidades de trabalho e renda, sendo peça-chave na consolidação de uma nação desenvolvida e democrática (PAULA, 2011, p. 56).

Nesse entendimento de que a democratização do acesso à educação é uma via, não exclusiva, para a promoção do crescimento econômico, desenvolvimento da sociedade e redução das desigualdades sociais, é necessário reconhecer o papel do Estado perante a sociedade na busca pela inclusão de grupos sub-representados na educação superior gratuita e de qualidade.

\section{O PAPEL DO ESTADO PERANTE A SOCIEDADE}

Estado e sociedade possuem relações singulares que estabelecem objetivos e parâmetros de organização para o desenvolvimento capitalista. De modo geral, o capitalismo apresenta duas tendências que se diferem pelo papel do Estado perante a sociedade: o Estado de Bem Estar Social (também conhecido como Keynesianismo) e o movimento Neoliberal.

De acordo com a ideologia Keynesiana, o Estado é responsável por ordenar o desenvolvimento econômico e social de um país através da garantia do pleno emprego e do conservadorismo econômico. Em contraposição, a ideologia neoliberal avulta a abertura comercial, a intervenção mínima do Estado e o respeito às leis de mercado.

Segundo OLIVEIRA (2003), a partir da década de 1930, introduz-se no Brasil um novo modelo econômico, com características quantitativas e qualitativas diferenciadas do modelo vigente. O modelo econômico agrário-exportador, concentrado na produção e exportação de bens primários (alimentos e matéria-prima) para a Europa e os EUA bem como na importação de produtos industrializados, passa por uma severa crise, efeito da crescente dívida externa. Neste cenário, instaura-se um novo modelo produtivo e econômico no país: o modelo urbano-industrial, caracterizado pela atuação intervencionista do Estado na economia e pelo processo de acumulação viabilizado pelo desenvolvimento industrial.

Entretanto, na década de 1980, a crise desencadeada pelo sucessivo aumento das dívidas externa e interna e pela hiperinflação, promove a decadência do modelo urbano-industrial, representado pelo Estado desenvolvimentista, este, fundamentado na substituição de importações e no incentivo ao crescimento do mercado interno e da urbanização.

\begin{tabular}{l|l|l|l|l|l} 
(C) Revista Triângulo & Uberaba, Minas Gerais & v.12 & n.1 & p. $103-118$ & 2019
\end{tabular}


No cenário mundial, a recessão econômica decorrente da crise do petróleo em 1973 impulsionou a ideologia neoliberal em boa parte dos países que seguiam a orientação de Estado de Bem Estar Social e Estado intervencionista. De acordo com MATOS (2008), as ideias neoliberais ganharam ênfase ao criticar a influência sindical e o movimento operário, uma vez que as bases de acumulação capitalista estavam sendo consumidas pelas reivindicações por aumento de salários e de gastos sociais. Neste novo contexto econômico, político e social, o Estado se tornaria parcimonioso em relação aos gastos sociais e minimamente participativo nas intervenções econômicas.

De forma geral, o neoliberalismo foi adotado como forma para superar a profunda recessão econômica e as altas taxas de inflação em busca de uma estabilidade econômico-financeira, mediante a contenção de gastos sociais e diversas reformas fiscais como incentivo aos agentes econômicos.

Conforme ressaltado por SOARES (2001), na década de 1980 o Brasil ocupava posição de destaque entre os países da América Latina em relação ao desenvolvimento industrial, sendo considerado o país da América Latina mais avançado industrialmente. Destarte, esta condição econômica do país retardou a estabelecimento da onda neoliberal no Brasil, o que segundo SOARES (2001) ocorreu no limiar da década de 1990.

Seguindo as tendências mundiais de materialização do neoliberalismo, com destaque para o governo Thatcher (Inglaterra), governo Reagan (Estados Unidos) e governo Kohl (Alemanha), o Brasil, a partir da década de 1990, não consegue manter o modelo urbano-industrial em razão da interdependência com outros blocos comerciais regionais, e acolhe os ideais neoliberais.

\begin{abstract}
O Brasil foi o último dos países latino-americanos, já no começo da década de 1990, a entrar nesse circuito de submissão às políticas de liberalização financeira e comercial e de desregulamentação cambial com o objetivo de atrair recursos externos, a qualquer custo, inserindo-se de forma subordinada no novo quadro financeiro mundial (TAVARES \& MELIN, 1998, p. 51).
\end{abstract}

Cabe ressaltar que o avanço da ideologia neoliberal em países em desenvolvimento como o Brasil sofreu forte influência do Consenso de Washington, ocorrido na capital dos EUA em 1989. Com base nesta recomendação internacional, os países deveriam promover ações de cariz neoliberal como forma de combate as crises econômicas. As recomendações traçadas aos países em desenvolvimento no Consenso de Washington abrangiam: abertura comercial entre países através da redução de tarifas alfandegárias; reforma fiscal, com diminuição de tributos pagos por grandes empresas; privatizações de empresas estatais e a sucessiva redução de gastos do Estado. Ficou estabelecido que os investimentos externos bem como a concessão de ajuda financeira por parte 
principalmente do Fundo Monetário Internacional (FMI) estariam condicionados ao cumprimento destas recomendações.

Neste contexto, no Brasil, passam a ser implementadas políticas neoliberais em conformidade com o modo de acumulação flexível, evidenciando a flexibilidade tanto dos produtos como dos mercados. Há, portanto, o objetivo de combater a inflação, além da busca por suscitar recursos externos através da liberalização comercial e da simplificação das regras cambiais. Outrossim, ganha ênfase a ideologia de Estado mínimo, onde apenas algumas atribuições essenciais permaneceriam como compromisso do Estado.

Desta forma abriu-se o leque de possibilidades de interferência internacional na elaboração de políticas públicas locais que garantissem a disponibilidade ao mercado de áreas até então de responsabilidade do Estado tais como, saúde, infra-estrutura e educação. (BENDRATH; GOMES, 2010, p.161).

Não obstante, as ações neoliberais no Brasil ocasionaram o agravamento da inflação no país, o aumento do desemprego e atingiram, em especial, os grupos sociais mais fragilizados economicamente, justamente por enfraquecer as políticas sociais. Apesar destes efeitos, que em um contexto geral, além de não promover o desenvolvimento econômico do país também não proporcionou um bem-estar social à maioria da população, as políticas neoliberais continuaram a ser implementadas pelos demais governantes do país, seguindo, portanto, as deliberações mundiais.

Destarte, a reestruturação produtiva e a ideologia neoliberal caracterizada pela acumulação flexível promoveram mudanças nos cenários econômico, político, social e cultural, que repercutiram em diversos setores da sociedade brasileira. Neste trabalho, interessa-nos os efeitos do neoliberalismo na educação, especificamente na educação superior.

\section{OS EFEITOS DO NEOLIBERALISMO NA EDUCAÇÃO SUPERIOR BRASILEIRA}

Para entender o atual panorama da educação superior no Brasil, torna-se relevante destacar a reconfiguração que esse nível de ensino vem sofrendo a partir da década de 1990, seguindo a lógica instituída pelos organismos internacionais como o Fundo Monetário Internacional (FMI), a Organização Mundial do Comércio (OMC), a UNESCO (Organização das Nações Unidas para Educação, Ciência e Cultura) e Banco Mundial que lançaram documentos que enfatizavam a necessidade de mudanças na educação superior, difundindo a ideia de democratização apoiada em 
condições favoráveis à privatização, diversificação das instituições e valorização do mérito individual (meritocracia). São exemplos destes documentos: Documento de Política para Mudança e o Desenvolvimento da Educação Superior (UNESCO, 1995), La Ensenanza Superior: Las lecciones derivadas de La experiencia (BANCO MUNDIAL, 1995), Declaração Mundial sobre o Ensino Superior no século XXI: visão e ação (UNESCO, 1998), A Educação Superior nos Países em Desenvolvimento: perigos e promessas (BANCO MUNDIAL, 2000).

Os baixos investimentos realizados pela União na área da educação superior, em grande medida ditados pelo processo de ajuste fiscal dos anos 1990, eram referendados pelas orientações emanadas dos organismos financeiros internacionais, tais como o Fundo Monetário Internacional (FMI) e o Banco Mundial, pelas quais os gastos em educação nos países em desenvolvimento deveriam limitar-se ao ensino básico. Com isso, aprofundou-se o fosso existente entre a crescente demanda por educação superior e a oferta de vagas pelas IES públicas, abrindo-se, assim, espaço para a expansão do setor privado (CORBUCCI; KUBOTA; MEIRA, 2016, p. 9).

A partir dos anos 90 o potencial da educação em se tornar um dos mais fortes mercados de serviços no século XXI passou a chamar a atenção de diversos analistas financeiros por apresentar altas taxas de rentabilidade com uma taxa de capitalização muito baixa (SANTOS, 2011). Cabe ressaltar que, além do destaque no campo econômico, a educação superior no Brasil auferiu valor político, uma vez que diversas políticas públicas educacionais têm sido formuladas e implementadas para este nível de ensino nos últimos anos.

O setor privado de ensino superior constitui uma parte relevante da economia brasileira e da geração de empregos. Como setor econômico, transformou-se, também, num poderoso grupo de interesses econômicos, com voz ativa na feitura das políticas públicas por meio de relevante participação no financiamento de campanhas para o Congresso Nacional. A disputa pela regulamentação do setor privado educacional tem importante impacto na vida do parlamento e na eleição de importantes líderes políticos à destra e à sinistra. Há políticos de todos os partidos associados ao setor privado educacional (NUNES, 2012, p. 46).

Seguindo a tendência mundial de seguimento da ideologia neoliberal, nos governos de Fernando Collor de Mello (1990-1992) e Fernando Henrique Cardoso (1995-2002), foram implementados programas e ações baseados na flexibilidade, competitividade e avaliação e que impactaram a educação superior no país, com fulcro na promulgação da Lei de Diretrizes e Bases da Educação Nacional (Lei n ${ }^{\circ}$ 9.394/1996) que aumentou ainda mais a heterogeneidade das instituições 
educacionais, pois até então, o setor privado compunha-se apenas de instituições sem fins lucrativos ${ }^{3}$ (confessionais e comunitárias). Conforme texto da LDBEN/1996 passou a compor o quadro de instituições, o modelo de estabelecimentos educacionais lucrativos:

Art. 20. As instituições privadas de ensino se enquadrarão nas seguintes categorias: I - particulares em sentido estrito, assim entendidas as que são instituídas e mantidas por uma ou mais pessoas físicas ou jurídicas de direito privado que não apresentem as características dos incisos abaixo;

II - comunitárias, assim entendidas as que são instituídas por grupos de pessoas físicas ou por uma ou mais pessoas jurídicas, inclusive cooperativas educacionais, sem fins lucrativos, que incluam na sua entidade mantenedora representantes da comunidade;

III - confessionais, assim entendidas as que são instituídas por grupos de pessoas físicas ou por uma ou mais pessoas jurídicas que atendem a orientação confessional e ideologia específicas e ao disposto no inciso anterior;

IV - filantrópicas, na forma da lei (BRASIL, 1996).

A flexibilidade promoveu a diversificação e diferenciação institucional, pois além das universidades outras instituições como centros universitários, faculdades, e institutos superiores de educação, ganharam espaço na oferta de cursos superiores no Brasil. As formas de acesso aos cursos superiores também foram flexibilizadas e o tradicional vestibular passou a ser uma entre outras modalidades de acesso ${ }^{4}$. Além disso, ganharam espaço os cursos de tecnologia e os cursos de educação a distância, medidas também instituídas pela LDBEN/1996.

A diversidade institucional e a diferenciação de cursos aliadas aos investimentos privados e redução de recursos repassados às instituições públicas ${ }^{5}$ impulsionaram a expansão das instituições privadas e, neste contexto, a competitividade foi incorporada ao sistema uma vez que este passou a ser orientado pelo mercado.

\footnotetext{
${ }^{3}$ De acordo com a Constituição Federal de 1988 (BRASIL, 1988), uma instituição educacional sem fins lucrativos gozará de benefícios fiscais, que podem ser imunidade ou isenção tributária, de acordo com a constituição jurídica e categoria administrativa. Nesse modelo institucional o mantenedor não é dono do patrimônio construído pela instituição.

${ }^{4}$ São consideradas novas formas de acesso o ENEM (que passou a ser utilizado para compor ou substituir os processos de seleção), a avaliação seriada (realizada ao longo do ensino médio), entrevistas e análise curricular.

${ }^{5}$ No Brasil, no governo de Fernando Henrique Cardoso, o Ministério da Educação, através do Programa de Recuperação e Ampliação dos Meios Físicos das Instituições de Ensino Superior e em parceria com o Banco Nacional de Desenvolvimento Econômico e Social (BNDES), viabilizou uma linha de financiamento de cerca de 750 milhões para instituições de ensino superior, com recursos provenientes de empréstimo do Banco Mundial. Estes recursos foram em grande parte canalizados para as universidades privadas. Desde 1999, o BNDES emprestou R \$ 310 milhões às universidades privadas e apenas $\mathrm{R} \$ 33$ milhões às universidades públicas (SANTOS, 2011, p. 33).
}

\begin{tabular}{l|l|l|l|l|l|} 
C Revista Triângulo & Uberaba, Minas Gerais & v.12 & n.1 & p. $103-118$ & 2019
\end{tabular}




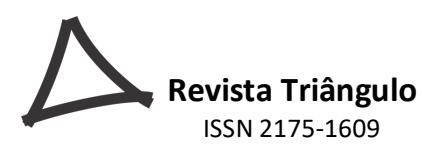

Em razão de maior flexibilidade e maior competitividade, foi instituído um sistema de avaliação da educação ${ }^{6}$, buscando assim mensurar os resultados atingidos pelas instituições de ensino superior e/ou cursos. Neste contexto, as inferências dessa atual forma do Estado atuar, denominado, por alguns pesquisadores, de Estado Avaliador (AFONSO, 2009; NEAVE, 2001; BALL, 2004), está na ampliação e no fortalecimento dos mecanismos de consolidação dos instrumentos de avaliação e regulação das políticas públicas implementadas.

Frente à essa conformação do papel do Estado, que defende a racionalidade técnica, eficiência e eficácia, institui-se em larga escala processos de monitoramento, avaliação e publicização dos resultados, tornando-se o instrumento incentivador da competitividade do mercado. De forma geral, o Estado Avaliador, é fruto da ideologia neoliberal, uma vez que coaduna com os objetivos de introduzir valor, resultados e lógica capitalista aos processos educacionais.

Ainda, seguindo as orientações dos organismos internacionais e a lógica instituída pelos valores neoliberais e em favor da liberdade de comércio para garantir o desenvolvimento econômico e social do país, em 2003, com a ascensão do governo Lula, algumas políticas educacionais foram formuladas, porém sem perder os princípios do mercado, caracterizado pela flexibilidade e competitividade.

Com a implementação destas políticas, o Estado financiou ações que apoiavam tanto as instituições de ensino privadas quanto os alunos da educação superior no país. São exemplos destas ações o Fundo de Financiamento Estudantil (FIES) e o Programa Universidade para Todos (PROUNI), onde o Governo Federal, com o discurso de democratizar a educação superior no país, transfere recursos para as instituições privadas ao mesmo tempo em que priva as instituições públicas de maiores investimentos.

Contudo, as desigualdades do sistema capitalista são reforçadas pela diferenciação do sistema de educação superior, dividindo cursos e instituições de acordo com o perfil dos estudantes: os estudantes de baixa renda e com menor capital social e cultural ingressam em cursos aligeirados, de curta duração, de menor prestígio social e em instituições de ensino de qualidade questionável e que em geral não se ocupam da pesquisa; os estudantes das elites dominantes e classes médias continuam ingressando majoritariamente em cursos com grande prestígio e em instituições de excelência (PAULA, 2011).

\footnotetext{
${ }^{6}$ Instituído em 1995, o Exame Nacional de Cursos - PROVÃO - tratava-se de um exame aplicado aos formandos dos diversos cursos de graduação, permitindo inclusive o estabelecimento de rankings entre cursos e instituições.

\begin{tabular}{l|l|l|l|l|l|l} 
C) Revista Triângulo & Uberaba, Minas Gerais & v.12 & n.1 & p. $103-118$ & 2019
\end{tabular}
}


Sendo assim, atualmente a educação superior no Brasil apresenta peculiaridades marcantes deste contexto neoliberal de incentivo à flexibilidade, competitividade e avaliação, e que tem influência direta nas instituições de ensino, no perfil discente, nos processos de ocupação de vagas e nas trajetórias políticas traçadas para este nível de ensino.

\section{A EXPANSÃO DA EDUCAÇÃO SUPERIOR BRASILEIRA A PARTIR DOS ANOS 90}

De acordo com o Censo da Educação Superior (CenSup) de 2017, no Brasil, o número de instituições de educação superior, separadas por organização acadêmica e categoria administrativa está distribuído conforme a Tabela 1, tendo grande representatividade as instituições privadas ${ }^{7}$, em especial as faculdades.

Tabela 1. Número de instituições brasileiras de educação superior, por organização acadêmica e categoria administrativa - Ano 2017.

\begin{tabular}{|c|c|c|c|c|c|c|c|c|}
\hline $\begin{array}{c}\text { Total de } \\
\text { Instituições }\end{array}$ & \multicolumn{3}{|c|}{ Universidade } & \multicolumn{2}{c|}{$\begin{array}{c}\text { Centro } \\
\text { Universitário }\end{array}$} & \multicolumn{2}{c|}{ Faculdade } & \multicolumn{2}{c|}{ IF e Cefet } \\
\cline { 2 - 10 } & Pública & Privada & Público & Privado & Pública & Privada & Público & Privado \\
\hline 2.448 & 106 & 93 & 08 & 181 & 142 & 1.878 & 40 & - \\
\hline
\end{tabular}

Fonte: INEP/ Sinopse Estatística da Educação Superior - 2017.

O predomínio de instituições privadas no Brasil denota uma tendência à mercantilização da educação superior, tornando a educação um objeto de interesse do capital. As instituições privadas possuem uma referência identitária com as empresas capitalistas, ou seja, estão muito voltadas para a obtenção do lucro (SILVA JÚNIOR e SGUISSARDI, 2000).

É oportuno ressaltar que o crescimento da rede privada de educação superior ganhou impulso quando o neoliberalismo se impôs como modelo do capitalismo, havendo a descapitalização das instituições públicas em benefício da globalização mercantil educacional.

A perda da prioridade na universidade pública nas políticas públicas do Estado foi, antes de mais, o resultado da perda geral de prioridade das políticas sociais (educação, saúde, previdência) induzida pelo modelo de desenvolvimento

\footnotetext{
${ }^{7}$ De acordo com o Censo da educação superior de 2017, as instituições privadas correspondem a 87,9\% do número de instituições de educação superior no Brasil.

\begin{tabular}{l|l|l|l|l|l|} 
(C) Revista Triângulo & Uberaba, Minas Gerais & v.12 & n.1 & p. $103-118$ & 2019
\end{tabular}
}


econômico conhecido por neoliberalismo ou globalização neoliberal, que a partir da década de 1980, se impôs internacionalmente (SANTOS, 2011, p. 18).

Considerando este cenário, o Gráfico 1 mostra o crescimento no número de instituições de ensino superior considerando a categoria administrativa, no período entre 1990 e 2017 . O Gráfico 2 demonstra a expansão de vagas no ensino superior nos últimos vinte e sete anos, considerando as sinopses estatísticas do INEP.

Gráfico 1. Número de IES brasileiras por categoria administrativa (1990 - 2017).

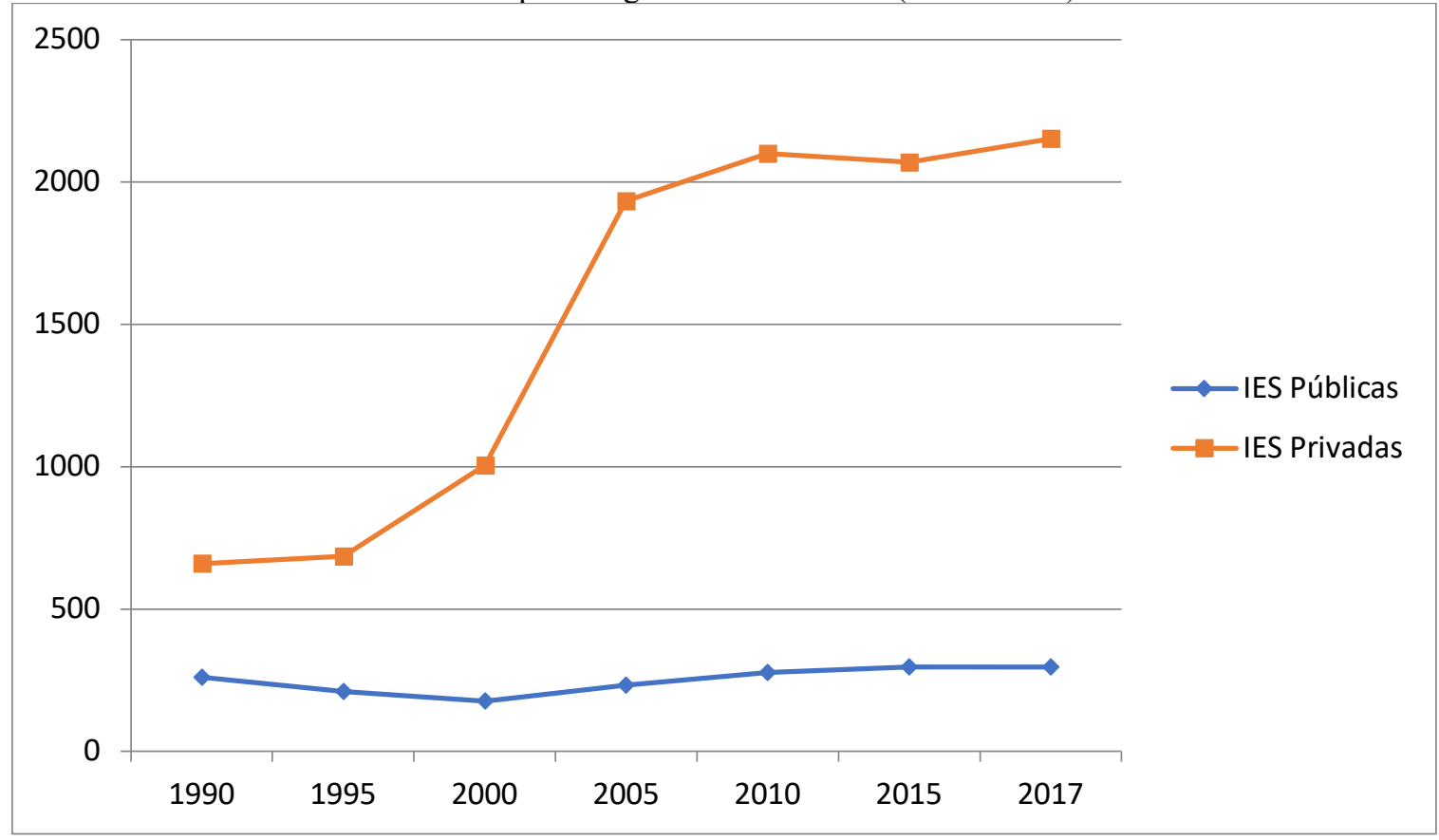

Fonte: Elaboração própria com base nos dados do INEP - 1990 a 2017.

Gráfico 2. Expansão de vagas de ensino superior no Brasil no período de 1990 a 2017. 


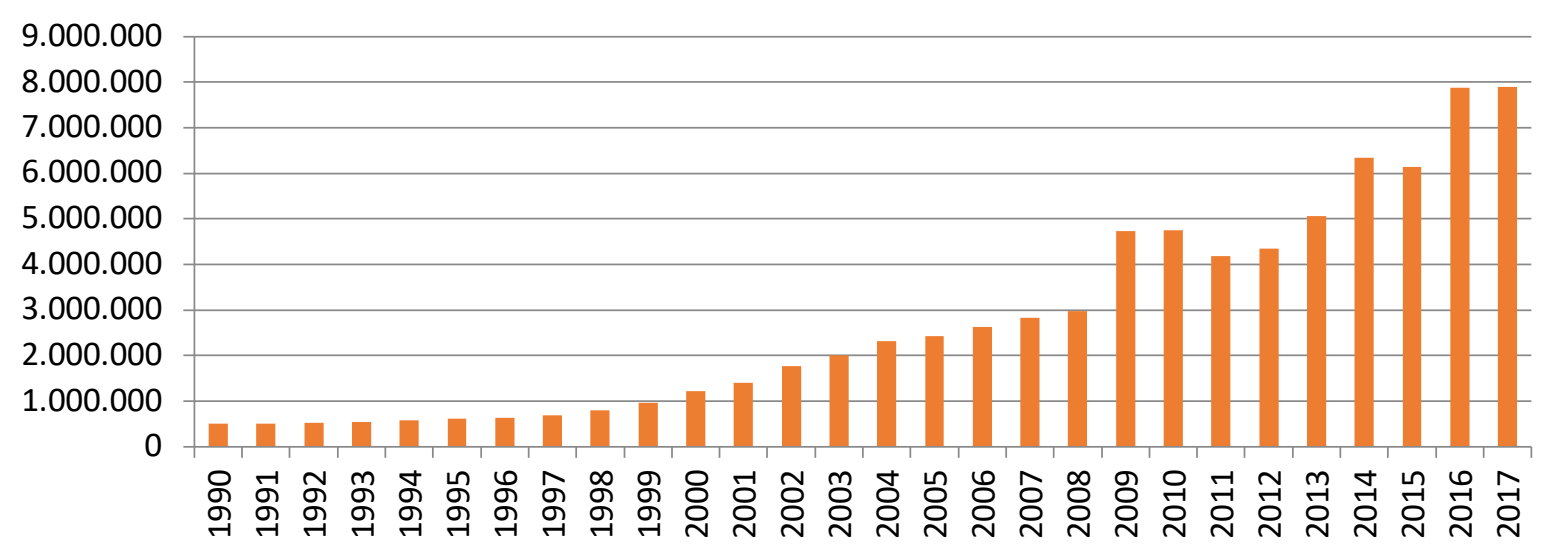

Fonte: Elaboração própria com base nos dados do INEP - 1990 a 2017.

Neste contexto, o número de matrículas na educação superior no Brasil tem aumentado ao longo dos anos, como é possível verificar no Gráfico 3. Porém, é importante esclarecer que o incremento no número de matrículas na educação superior não significa necessariamente a inclusão dos grupos sub-representados neste nível de ensino, afinal, democratização difere-se de massificação.

Gráfico 3. Evolução de matrículas na educação superior brasileira - 1990 a 2017.

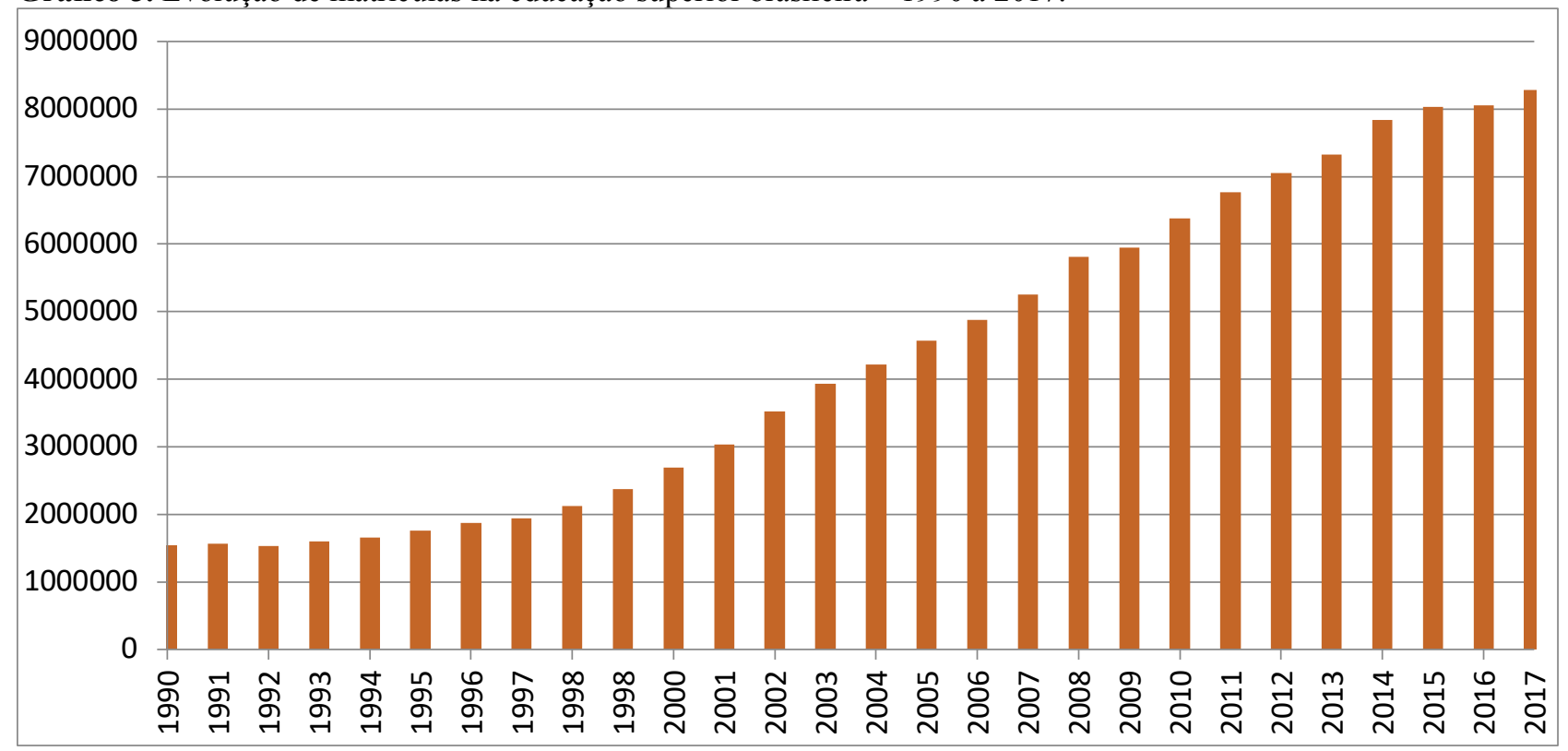

Fonte: Elaboração própria com base nos dados do INEP - 1990 a 2017.

Enquanto na massificação apenas os aspectos quantitativos são considerados, a democratização da educação superior somente será efetiva se aliada à qualidade do ensino oferecido

\begin{tabular}{l|l|l|l|l|l|} 
(C) Revista Triângulo & Uberaba, Minas Gerais & v.12 & n.1 & p. $103-118$ & 2019
\end{tabular}


à todos como garantia de direito social. Segundo LUZ (2013, p.33), "o processo de democratização é uma ação utilizada como forma de lutas pelos direitos sociais" e que concebe mudanças na direção da democracia.

A transformação da educação superior em mercadoria ou serviço comercial caracteriza-se em um processo de massificação mercantilizadora, impedindo a efetiva democratização deste nível de ensino (SGUISSARD, 2015). No entendimento deste autor, para não ser caracterizado como um processo de massificação, a educação superior deve apresentar igualdade de condições de acesso e escolha de cursos, além de garantir a permanência e o êxito.

Desta forma, as políticas públicas de expansão da educação superior brasileira tem demonstrado sua importância, porém devem ser formuladas e implementadas com vistas à inclusão dos grupos marginalizados. Além disso, é fundamental analisar de que forma esta expansão tem ocorrido: a diversidade de instituições e a diferenciação de cursos aliados ao crescimento do número de matrículas indica qualidade do ensino superior no país? Os grupos sub-representados estão conseguindo ingressar em cursos de prestígio social e em instituições de qualidade? Em caso negativo, o efeito da expansão da educação superior trata-se apenas de um processo de massificação e não de democratização.

\section{CONSIDERAÇÕES FINAIS}

Cada vez mais a educação deve ser encarada como um mecanismo importante de ascensão social. Será por meio da educação que os indivíduos até então marginalizados da sociedade serão capazes de buscar alternativas que melhorem sua qualidade de vida; será por meio da educação que se sentirão capacitados para lutar contra a reprodução social.

A "cultura", supostamente, garantida pelo diploma escolar, é um dos componentes fundamentais do que faz o homem realizado em sua definição dominante, de modo que a privação é percebida como uma mutilação essencial que atinge a pessoa em sua identidade e dignidade de homem, condenando-a ao silêncio em todas as situações oficiais em que tem de "aparecer em público", mostrar-se diante dos outros com seu corpo, sua maneira de ser e sua linguagem (BOURDIEU, 2017, p. 363).

As políticas educacionais não visam apenas ampliar necessariamente o quantitativo da oferta de vagas na educação superior, contudo, pretende redistribuir o módulo do vetor de acesso, que é 
maior para as classes economicamente mais favorecidas, de forma a proporcionar oportunidades aos segmentos social e historicamente excluídos.

Estas políticas são de grande importância principalmente para os setores historicamente negligenciados do ensino superior, como negros, pardos, indígenas e/ou pessoas em situação de vulnerabilidade econômica, pois, interferem diretamente nos processos de organização e gestão das instituições na busca pela democratização deste nível de ensino, e por isso, devem ser frequentemente avaliadas e/ou melhoradas, se for o caso.

Como reflexo de toda a trajetória histórica do sistema de ensino superior no Brasil, extremamente elitista e privatizado, e das evidências de necessidade de políticas que realmente melhorem as possibilidades de acesso, permanência e êxito neste nível de ensino, é importante analisar a eficiência destas políticas, e principalmente propor novas reflexões que poderão subsidiar melhores resultados com vistas à expansão da educação superior associada à qualidade do ensino oferecido de forma democrática, ou seja, com vistas à democratização da educação superior.

Destarte, é essencial não confundir democratização do acesso e inclusão social com dados puramente estatísticos de crescimento do número de instituições, vagas e matrículas. A democratização da educação superior somente será efetiva se, além da ampliação de vagas e expansão de matrículas for assegurado aos grupos marginalizados meios de permanência e um ensino de qualidade para todos.

\section{REFERÊNCIAS}

AFONSO, Almerindo Janela. Avaliação educacional: regulação e emancipação. 4. ed. São Paulo: Cortez, 2009.

BALL, Stephen J. Performatividade, privatização e o pós-Estado do bem-estar. Educação \& Sociedade. Campinas, v. 25, n.89, p. 1105-1126, set/dez. 2004.

BANCO MUNDIAL. A Educação Superior nos Países em Desenvolvimento: perigos e promessas. Washington, 2000.

. La Ensenanza Superior: Las lecciones derivadas de La experiência. Washington, 1995.

BENDRATH, E. A.; GOMES, A. A. Estado, políticas públicas e organismos internacionais: a educação no foco do debate. Intermeio. UFMS, MS, v.16, n.32, 2010, p.157-171.

BOURDIEU, Pierre. A distinção: crítica social do julgamento. Trad. Daniela Kern; Guilherme J. F. Teixeira. 2. ed. rev. 4. reimpr. Porto Alegre, RS: Zouk, 2017.

\begin{tabular}{l|l|l|l|l|l|} 
(C) Revista Triângulo & Uberaba, Minas Gerais & v.12 & n.1 & p. $103-118$ & 2019
\end{tabular}


BRASIL. Lei n 13.005, de 25 de junho de 2014. Aprova o Plano Nacional de Educação PNE e dá outras providências. Disponível em: $<$ http://www.planalto.gov.br/ccivil_03/_ato20112014/2014/lei/113005.htm>. Acesso em: 28 jul. 2018.

. Lei $n^{0}$ 9.394, de 20 de dezembro de 1996. Estabelece as diretrizes e bases da educação nacional. Disponível em: < http://www.planalto.gov.br/ccivil_03/leis/L9394.htm>. Acesso em: 04 jul. 2018.

. Constituição Federal de 1988. Promulgada em 5 de outubro de 1988. Disponível em

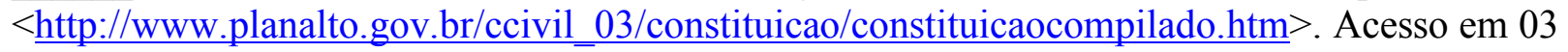
ago. 2018.

CORBUCCI, Paulo Roberto; KUBOTA, Luis Claudio; MEIRA, Ana Paula Barbosa. A evolução da educação superior privada no Brasil: da Reforma Universitária de 1968 à década de 2010. Radar. n. 46 , ago. 2016.

INSTITUTO NACIONAL DE ESTUDOS E PESQUISAS EDUCACIONAIS ANÍSIO TEIXE RA. Sinopse Estatística da Educação Superior 1999-2017. Brasília: Inep, 2017.

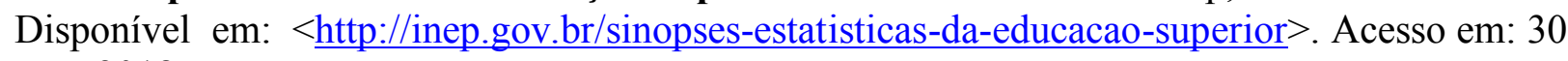
nov. 2018.

. Evolução do Ensino Superior - Graduação 1980 -1998. Brasília: Inep, 2000.

Disponível em: $<$ http://download.inep.gov.br/download/censo/1998/superior/evolucao_19801998.pdf>. Acesso em: 30 nov. 2018.

LIMA, Lucinete Marques; BIANCHINI, Angelo Rodrigo. Seletividade e/ou democratização da educação superior em tempos de Sisu. Disponível em: $<$ http://www.periodicoseletronicos.ufma.br/index.php/rppublica/article/view/6187>. Acesso em: 10 jul. 2018.

LUZ, Jackeline Lourenço Noronha da. O Sistema de Seleção Unificada (SiSU) na Universidade Federal de Mato Grosso - campus Cuiabá - e a relação com a democratização do acesso. 2013. 186 f. (Dissertação de Mestrado). Programa de Pós-Graduação em Educação, Universidade Federal do Mato Grosso, Cuiabá-MT, 2013.

MATOS. Sidney Tanaka de Souza. Conceitos primeiros de neoliberalismo. Mediações. v.13, n. 12, p. 192-213, jan/jun e jul/dez. 2008

NEAVE, Guy. Reconsideración del estado avaliador. In: NEAVE, Guy. Educación superior: histórica e política. Barcelona: Gedisa, 2001.

OLIVEIRA, Francisco. Crítica à razão dualista: o ornitorrinco. São Paulo: Boitempo Editorial, 2003.

PAULA, Maria de Fátima Costa de. Educação superior e inclusão social na América Latina: um estudo comparado entre Brasil e Argentina. In: PAULA, Maria de Fátima Costa de; LAMARRA,

\begin{tabular}{l|l|l|l|l|l|l} 
(C) Revista Triângulo & Uberaba, Minas Gerais & v.12 & n.1 & p. 103 - 118 & 2019
\end{tabular}


Norberto Fernandez (orgs.). Reformas e democratização da Educação Superior no Brasil e na América Latina. Aparecida, SP: Ideias \& Letras, 2011.

REIS, Julio Adriano Ferreira dos et al. Estrutura do ensino superior brasileiro: um diagnóstico estratégico societário. Rebrae - revista brasileira de estratégia. Curitiba, v.7, n.1, p. 88-99, jan./mar. 2014.

SANTOS, Boaventura de Sousa. A universidade no século XXI: para uma reforma democrática e emancipatória da universidade. 3. ed. São Paulo: Cortez, 2011.

SOARES, L. Tavares. Ajuste neoliberal e desajuste social na América Latina. Petrópolis; RJ: Vozes, 2001.

SGUISSARDI. Valdemar. Educação Superior no Brasil: Democratização ou massificação mercantil. Educação \& Sociedade. Campinas. v. 36, n. 133, p. 867-889, out./dez. 2015.

SILVA JÚNIOR, João dos Reis; SGUISSARDI, Valdemar. A educação superior privada no Brasil: novos traços de identidade. In: SGUISSARDI, Valdemar (Org.). Educação superior: velhos e novos desafios. São Paulo: Xamã, 2000. p. 155-177.

TAVARES, Maria da Conceição; MELIN, Luiz Eduardo. Mitos globais e fatos regionais. In: FIORI, José Luís et al. Globalização: o fato e o mito. Rio de Janeiro: EdUERJ, 1998. p. 41-54.

UNESCO. Declaração Mundial sobre Ensino Superior no século XXI: visão e ação. Paris, 1998. . Documento de política para el cambio y l desarrolo em La educación superior. Paris, 1995.

\begin{tabular}{|l|l|}
\hline & Recebido em: 14 Dez. 2018 \\
\hline & Aprovado em: 18 Abr. 2019 \\
\hline
\end{tabular}

